\title{
Optimization and scaling up of a biotechnological synthesis of natural green leaf volatiles using Beta vulgaris hydroperoxide lyase
}

\author{
Cedric Gigot $^{\mathrm{a}, *}$, Marc Ongena $^{\mathrm{a}}$, Marie-Laure Fauconnier ${ }^{\mathrm{b}}$, Yordan Muhovski ${ }^{\mathrm{d}}$, Jean-Paul Wathelet ${ }^{\mathrm{c}}$, \\ Patrick du Jardin ${ }^{\mathrm{b}}$, Philippe Thonart ${ }^{\mathrm{a}}$ \\ a Walloon Center of Industrial Biology, Université de Liège - Gembloux Agro-BioTech, Passage des Déportés 2, B-5030 Gembloux, Belgium \\ b Plant Biology Unit, Université de Liège - Gembloux Agro-BioTech, Passage des Déportés 2, B-5030 Gembloux, Belgium \\ c General and Organic Chemistry Unit, Université de Liège - Gembloux Agro-BioTech, Passage des Deportes 2, B-5030 Gembloux, Belgium \\ ${ }^{d}$ Department of Biotechnology, Walloon Agriculture Research Center, Chaussée de Charleroi 238, B-5030 Gembloux, Belgium
}

\section{A R T I C L E I N F O}

\section{Article history:}

Received 2 February 2012

Received in revised form 13 July 2012

Accepted 16 July 2012

Available online $\mathrm{xxx}$

\section{Keywords:}

Green leaf volatile

Natural aroma

Oxylipins

Hydroperoxide lyase

Lipoxygenase

Beta vulgaris

\begin{abstract}
A B S T R A C T
Following a promising preliminary study concerning sugar beet leaves valorization and to fulfill the high demand in natural $\mathrm{C}_{6}$-aldehydes flavors, an efficient biocatalytic reaction was developed to synthesize (2E)-hexenal at large scale. As major product of the lipoxygenase enzyme, 13-HPOT was converted by sugar beet hydroperoxide lyase extracted from leaves or expressed by recombinant Escherichia coli strains. With the adaptation of a fed-batch substrate addition and a continuous extraction of volatiles, $3.46 \mathrm{mM}$ and $1.37 \mathrm{mM}$ of $\mathrm{C}_{6}$-aldehydes were produced with the native hydroperoxide lyase at respectively 2 and $100 \mathrm{~L}$ scale. Furthermore, higher molar productivity of green leaf volatiles was reached with recombinant hydroperoxide lyase $(5.5 \mathrm{mM}$ at $2 \mathrm{~L}$ scale) while no others side products from the lipoxygenase pathway were formed. Once purified, these natural aromas are suitable for food and beverage preparations, perfumes or cosmetic products.
\end{abstract}

(c) 2012 Elsevier Ltd. All rights reserved.

\section{Introduction}

Green note is one of the most attractive flavor in the aroma industry conferring freshness and authenticity to goods [1]. This odor is composed of different molecules collectively named green leaf volatiles (GLVs) suggesting that these compounds are usually synthesized in green organs of plants [2]. Chemically, GLVs are C6-or C9-aldehydes and alcohols formed through the lipoxygenase (LOX) pathway. LOX catalyzes the stereospecific oxygenation of the ninth or thirteenth carbon of C18-(PUFAs) (poly unsaturated fatty acids) forming fatty acid hydroperoxides (HPOs) [3]. These hydroperoxy PUFAs are substrates for multiple enzymes leading to the synthesis of a diverse group of metabolites collectively called oxylipins. This group includes signaling compounds such as jasmonic acid, anti-microbials such as divinyl ethers, and a plant-specific blend of volatiles including GLVs produced by hydroperoxide lyase (HPL) [4]. The synthesized

\footnotetext{
* Corresponding author. Tel.: +32 479227154; fax: +32 81614222.

E-mail addresses: c.gigot@ulg.ac.be, cedric.gigot@gmail.com

(C. Gigot), marc.ongena@ulg.ac.be (M. Ongena), marie-laure.fauconnier@ulg.ac.be (M.-L.Fauconnier), muhovski@cra.wallonie.be(Y.Muhovski),jp.wathelet@ulg.ac.be (J.-P. Wathelet), patrick.dujardin@ulg.ac.be (P. du Jardin), p.thonart@ulg.ac.be (P. Thonart).
}

C6 and C9-aldehydes can be transformed in their corresponding diastereoisomers or in alcohols respectively by an isomerase (ISO) (or by spontaneous reactions) and by an alcohol dehydrogenase $(\mathrm{ADH})[5,6]$. Stereospecificities of these reactions are essential, and aroma properties of the GLV clearly depend on the molecular structure. Among GLVs, (2E)-hexenal and (3Z)-hexenol are the most valuable products retaining various flavor applications and higher stability.

According to this description, all higher plants with green organs are potential sources for GLVs. As a matter of fact, several patents have already been deposited concerning GLVs extraction and biosynthesis using plants organs, such as soybean leaves [7], strawberry leaves [8], muskmelon leaves [9] or watermelon fruits [10]. In these industrial productions of GLV, soybean LOX is commonly used to produce HPOs from vegetal oil with high yields. The next transformation step depends on the HPL enzymatic activity of the selected plant, and may be limited by its extractability, stability and specificity. HPL activity was first measured in watermelon seedlings [11], tea leaves [12], alfalfa seedlings [13], soya leaf [14], spinach leaves [15] and olive fruits [16]. However the enzymatic mechanism was completely elucidated only a few years ago $[17,18]$. HPL enzymes act as isomerases performing homolytic rearrangements of HPOs into transient hemiacetals which upon decomposition produce aldehydes and acids. During this reaction, HPL may display a suicidal behavior, being irreversibly inhibited

1359-5113/\$ - see front matter (c) 2012 Elsevier Ltd. All rights reserved. http://dx.doi.org/10.1016/j.procbio.2012.07.018 
by its own substrate [19]. This problem entails biotechnological issues, such as the necessity of larger amount of plant HPL to achieve the transformation of highly concentrated substrates. Furthermore, HPL is a chloroplast membrane-bound enzyme with a reduced stability, especially when extracted or exposed to extreme temperatures below $0^{\circ} \mathrm{C}$ or above $45^{\circ} \mathrm{C}$. Therefore the flavor industry is constantly searching for new plant materials containing valuable HPL content [20].

Based on a preliminary study about sugar beet valorization, we have observed that leaves contain significant amounts of 13-HPOT degrading HPL [21]. Therefore, attempts for GLVs production were performed at low scale; but the aromas produced were rapidly consumed by undesirable enzymatic reactions. In this present work, we study the optimization of the biotransformation of HPOs into GLVs using novel biotechnological improvements, such as modulated substrate addition and continuous products extraction. This novel reaction process reduces the influence of the HPL instability, the substrate inhibition and the parasitic consumption. Scaling up to $100 \mathrm{~L}$ and recuperation of the aroma is also successfully developed to complete the process. Finally to suppress any agricultural related restriction, use of recombinant BvHPL produced by prokaryote strains was also evaluated.

\section{Materials and methods}

\subsection{Materials}

Sugar beet leaves from different varieties were collected from the field. After being washed twice with tap water and dried on absorbent paper, they were directly stored at $-80^{\circ} \mathrm{C}$. Before experiments, leaves were crushed in a mortar under liquid nitrogen and then transferred in refrigerated IKA mill for a 2 min treatment at full speed to obtain a fine powder. 13-HPOT used for biotechnological production is produced according to Gardner [22].

\subsection{RACE-PCR for BvHPL gene}

Total RNA was extracted from $10 \mathrm{mg}$ of leaves according to the Trizol method (Invitrogen, Carlsbad, United States). Full length cDNA was synthesized thanks to the SuperScript ${ }^{\mathrm{TM}}$ Double-Stranded cDNA Synthesis Kit (Invitrogen, Carlsbad, United States). Afterwards adapters were ligated to the full sequence at both $3^{\prime}$ and $5^{\prime}$ ends, and RACE-PCR was performed with Hifi-Taq polymerase (KAPA Biosystems, Boston, United States). First, degenerated primers were designed based on the conserved sequences of four HPLs [23-26]. After a first successful partial amplification of the BvHPL gene, four gene specific primers were designed for further amplifications (Forward R1: 5'-CCAAGTTCACGGGGATAGGAGAGTTGGTG3'; R2: 5'-GTGTAATTTAGCCTATCCCCTATCGG-3'; Upstream R3: 5'-CCAAGTTCACGGGGATAGGAGAGTTGGTG-3'; R4: 5'-AAGGTTAAAACCCCCTGTACCACTTC-3'). All primers were purchased from Eurogentec (Liège, Belgium), and sequencing of PCR product was performed at the GIGA bio-facilities (Liège, Belgium) by the dideoxy chain termination method.

\subsection{Transformation of Escherichia coli and enzyme production}

By PCR, KpnI and HindIII restriction sites were introduced at the $5^{\prime}$ and $3^{\prime}$ ends of the BvHPL gene, respectively, using the downstream and upstream primers C1 5'-GTCGGTACCTGCCGCTCCGCACACTCCCGGGTGGCT-3' and C2 5'CAGTCAAGCTTTCACTTAGCTTTCTCAACTCCCGTGATTGC-3'. The C2 primer carried the natural HPL stop codon. The PCR product obtained with the primers was digested by KpnI and HindIII, dephosphorilated and ligated into the pQe-31 vector. Ligated vector was propagated into E. coli M15 according to the manufacturer's protocol (QIA express KIT Type IV, Qiagen, Venlo, Netherlands). When the presence of the BvHPL gene was confirmed into the vector by enzyme digestion and PCR, larger culture were performed for recovery and extraction of larger amounts of the enzyme. Recombinant HPL was produced in flasks or in bioreactors containing from $100 \mathrm{~mL}$ to $1 \mathrm{~L}$ of TB medium with $200 \mathrm{mg}$ of ampicillin/L, $50 \mathrm{mg}$ of kanamycin/L and aminolevulinic acid $2.5 \mathrm{mM}$, culture conditions are as follow. First, temperature is maintained at $37^{\circ} \mathrm{C}$ and agitation at $600 \mathrm{rpm}$ till the optical density reach 1 . After, induction is performed by addition of IPTG to a concentration of $0.1 \mathrm{mM}$ followed by a temperature drop to $18^{\circ} \mathrm{C}$. Culture is pursued for $72 \mathrm{~h}$ before being stopped and cooled down at $4{ }^{\circ} \mathrm{C}$. $10 \mathrm{~mL}$ of $E$. coli culture are centrifuged for $20 \mathrm{~min}$ at $4{ }^{\circ} \mathrm{C}$ and $10,000 \times g$. The supernatant is discarded; the pellet is washed in phosphate buffer $\mathrm{pH} 7.7$ and centrifugated with the previous procedure. Extraction of the pellet is realized by addition of $1 \mathrm{~mL}$ of lysis buffer (lysozyme $5 \mathrm{mg} / \mathrm{mL}, \mathrm{PMSF}, \mathrm{MgCl}_{2}$, DNAseI, $\mathrm{NaCl}$ and Triton $\mathrm{X}-100 \mathrm{0.2} \%$ ) under agitation at $4{ }^{\circ} \mathrm{C}$ for $30 \mathrm{~min}$. After a new centrifugation $\left(25,000 \times \mathrm{g}, 4^{\circ} \mathrm{C}, 10 \mathrm{~min}\right)$, supernatant is recovered and consist in the crude extract.

\subsection{Volatile analysis and HPL activity assays}

Volatile products contained within the leaves are extracted from previously crushed plants by the Lickens-Nikerson method with diethyl ether as extraction solvent. The identification analysis is carried out on these extracts by GCMS on CP-WAX52CB column ( $30 \mathrm{~m} \times 0.25 \mathrm{~mm}, 0.15 \mu \mathrm{m}$, Chrompack, The Nederland). On column injector was used from $50^{\circ} \mathrm{C}$ to $230^{\circ} \mathrm{C}$. Oven temperature was initially $50^{\circ} \mathrm{C}$ and rose to $240^{\circ} \mathrm{C}$ at $8^{\circ} \mathrm{C} / \mathrm{min}$. Helium flow was $0.8 \mathrm{~mL} / \mathrm{min}$. MS conditions of the Agilent 5975 were as follows: mass scan range $m / z 60-450$, source temperature $200^{\circ} \mathrm{C}$ and ionization voltage $70 \mathrm{eV}$. Quantitative analysis is done on $6890 \mathrm{HP}$ Chromatograph by GC FID with the same chromatographic conditions using octanal as internal standard. Assays for HPL activity were performed by gas chromatography in the same condition as above. $5 \mathrm{~g}$ of crushed leaves were extracted during $30 \mathrm{~min}$ at $4{ }^{\circ} \mathrm{C}$ in a pH 6.7 phosphate buffer containing $3 \mathrm{mM}$ EDTA, $5 \mathrm{mM}$ cysteine and $0.1 \%$ of triton $\mathrm{X}-100$. Solution was centrifuged and the supernatant consists in the crude extract. In a sealed tube, $100 \mu \mathrm{L}$ of the crude extract were added to $2900 \mu \mathrm{L}$ of phosphate buffer containing 13-HPOT and heptanal as internal standard. Reaction was realized during $1 \mathrm{~min}$ at $25^{\circ} \mathrm{C}$ and stopped by addition of $500 \mu \mathrm{L}$ of $10 \% \mathrm{H}_{2} \mathrm{SO}_{4}$. Extraction of GLVs was performed by hexane solvent saturated in $\mathrm{MgSO}_{4}$ salt.

\subsection{Green leaf volatile production in bioreactor}

Production assays were performed in closed and sealed Biolafitte bioreactors (volume 1-100 L). The substrate, an alcoholic solution of 13-HPOT, is dried under nitrogen flow and hydroperoxides are suspended in a $50 \mathrm{mM}$ phosphate buffer solution at $\mathrm{pH} 7.5$. HPL enzymatic source is added to the solution to a level of $0.8 \mu \mathrm{kat} / \mathrm{mL}$ (1 katal activity corresponding to the transformation of $1 \mathrm{~mol}$ of any hydroperoxide into $1 \mathrm{~s}$ ), and powerful shaking is performed at $600 \mathrm{rpm}$ in $2 \mathrm{~L}$ volume and $300 \mathrm{rpm}$ in $100 \mathrm{~L}$. The reaction conditions are maintained during $2 \mathrm{~min}$ at small scale and during $30 \mathrm{~min}$ at large scale. Substrate addition is performed by batch of different substrate concentrations or by fed-batch to reach a final concentration of $10 \mathrm{mM}$ (at $2 \mathrm{~L}$ scale: $7.5 \mathrm{mmol} / \mathrm{min}$; at $100 \mathrm{~L}$ scale: $25 \mathrm{mmol} / \mathrm{min}$ ). Reactions are stopped by acidification at $\mathrm{pH}$ below 4 by addition of $10 \% \mathrm{H}_{2} \mathrm{SO}_{4}$. Two different modes of GLVs extraction were adapted during our experiments. First, a classical extraction system according to Noordermeer [27], bioreactor juice was filtered and injected into a preparative solid phase extraction column containing Purolite Macronet MN-202, a hydrophobic resin. Adsorbed compounds are eluted with ethanol. Secondly, a continuous extraction procedure composed of air flow at $40^{\circ} \mathrm{C}$ injected at $8 \mathrm{~L} / \mathrm{min}(2 \mathrm{~L})$ and $96 \mathrm{~L} / \mathrm{min}$ $(100 \mathrm{~L})$ is adapted at the bottom of the bioreactor. Volatile compounds are extracted by air flow are driven through a cold trap at $-70^{\circ} \mathrm{C}$ for condensation. Afterwards, cold trap content is washed by hexane containing internal standard octanal. GC analyses on both extracts are conducted as previously explained. Yield calculation is obtained by addition of GLVs extracted by both techniques and expressed in function of the initial bioreactor volume.

\section{Results and discussion}

\subsection{Optimization and scaling up}

In the last years, industrials have developed several (2E)hexenal and (3Z)-hexenol production processes from various plant materials [28-30]. These production assays were performed at very

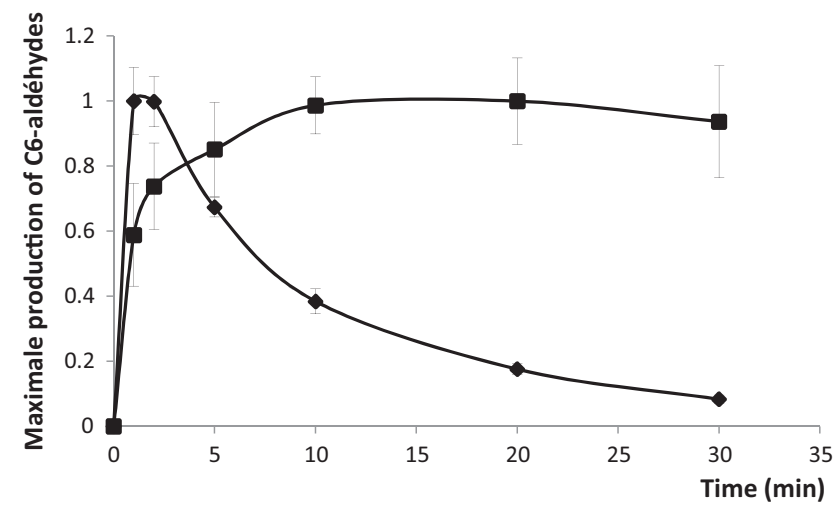

Fig. 1. Kinetics synthesis of GLVs at two different scale of bioreactor $2 \mathrm{~L}$ scale ( and $100 \mathrm{~L}$ scale $(\mathbf{\square})$. Condition of production is standard: $0.5 \mu \mathrm{kat} / \mathrm{mL}$ and substrate 13-HPOT at $5 \mathrm{mM}$. Level $100 \%$ corresponding to the maximum level of GLVs obtained during the reaction. 


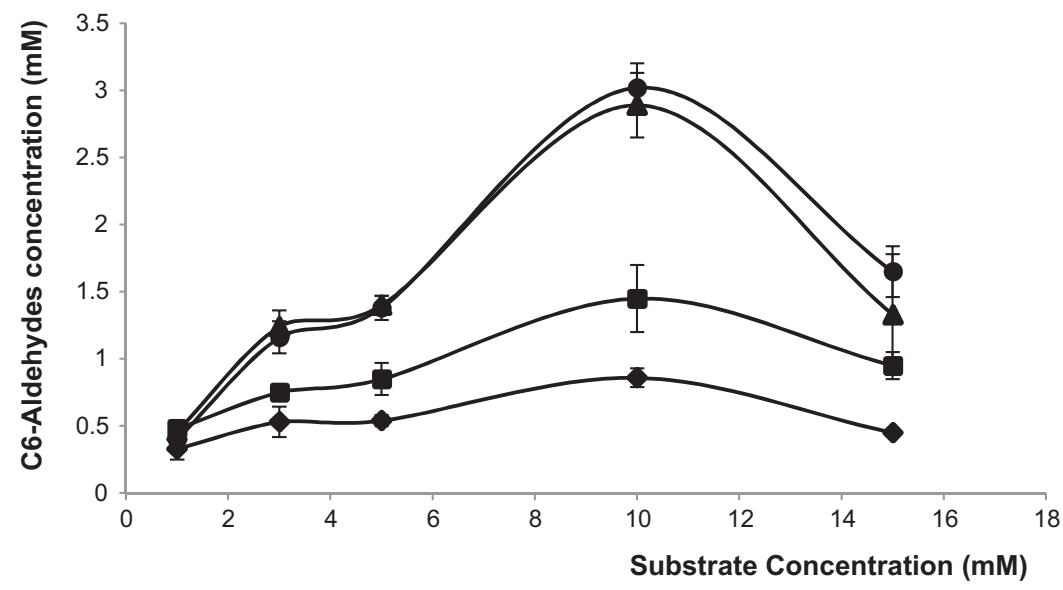

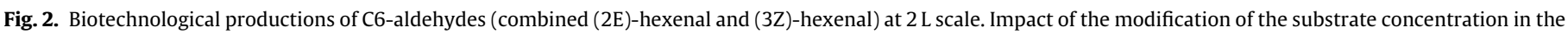
bio-reactor with different enzyme concentrations: $0.2 \mu \mathrm{kat} / \mathrm{mL}(\bullet) ; 0.4 \mu \mathrm{kat} / \mathrm{mL}(\boldsymbol{\nabla}) ; 0.6 \mu \mathrm{kat} / \mathrm{mL}(\boldsymbol{\Delta}) ; 0.8 \mu \mathrm{kat} / \mathrm{mL}(\bullet)$.

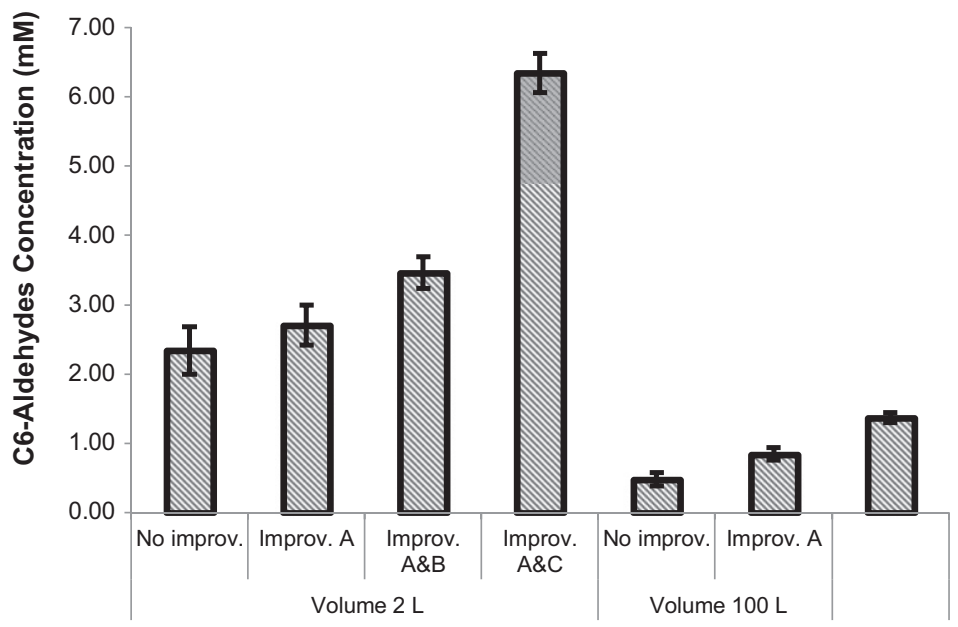

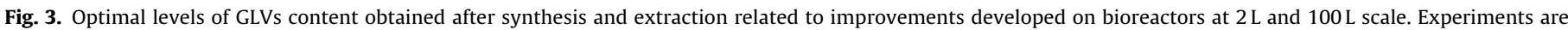

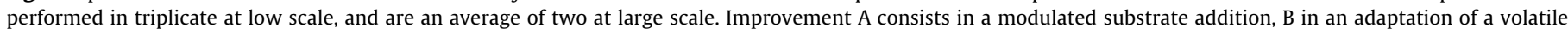
extraction by air flow, and C correspond to the use of recombinant HPL from $E$. coli as source of enzyme.

small scale between 2 and $10 \mathrm{~mL}$, and final $\mathrm{C}_{6}$-aldehyde concentrations reached approximately $10 \mathrm{mM}$. During a previous work, we have observed that in sugar beet leaves, GLVs producing pathway is clearly oriented toward $\mathrm{C}_{6}$-aldehydes synthesis with high amount of 13-HPL activity: $9.54 \mu \mathrm{kat} / \mathrm{g}$ of sugar beet leaves. In this context, assays for (3Z)-hexenal and (2E)-hexenal production from 13-HPOT were performed in mixed bio-reactor from $2 \mathrm{~L}$ to $100 \mathrm{~L}$ with crushed beet leaves. Kinetics of this reaction strongly depends on the bioreactor volume (Fig. 1). HPL transformation of 13-HPOT into GLVs was very fast but without any enzymatic extraction or purification, the freshly produced aldehydes were consumed by other plant enzymes leading to high underestimation of the GLVs quantities actually formed [21].

Due to this product loss, determining the optimal conditions for the reaction will highly depend on both enzyme and substrate concentrations. At the laboratory scale, the best result is a $2.71 \mathrm{mM}$ solution of GLVs obtained in $2 \mathrm{~min}$ from a $10 \mathrm{mM}$ concentration of substrate and $0.8 \mu \mathrm{kat} / \mathrm{mL}$ activity (Fig. 2). Scale up of the process was performed in $100 \mathrm{~L}$ bioreactor (Fig. 3 ). The increased volume modifies the reactor hydrodynamic and reactions are slower due to the longer homogenization time. In these conditions, production was the highest after $30 \mathrm{~min}(0.84 \mathrm{mM})$ and productivity was significantly reduced in the same condition compared to lower scale assay (Fig. 3).
HPL presents a suicidal behavior in the presence of high concentration of substrate, and we therefore tested fed-batch addition (Improvement A). HPOs were added continuously during the whole reaction time. Afterwards, a gas collecting system was adapted to extract volatile compounds from the reaction medium by injection of heated air at the bottom of the bio-reactor (Improvement B). Compounds with low saturation vapor pressure are driven by the air flow from the solution to a cold trap at $-70^{\circ} \mathrm{C}$ to be condensed. Experiments show that $8 \mathrm{~L} / \mathrm{min}$ air flow at $40^{\circ} \mathrm{C}$ allowed recovering most of the aldehydes from a $10 \mathrm{mM}$ solution in $10 \mathrm{~min}$ (data not shown). At the $2 \mathrm{~L}$ scale, combination of these two improvements can increase the final GLVs concentration to $3.5 \mathrm{mM}$ when using $10 \mathrm{mM}$ substrate (Fig. 3). At higher scale, hydrodynamic stress and impossibility to provide a $400 \mathrm{~L} / \mathrm{min}$ air flow limited the efficiency of the extraction, but concentration raised from 0.84 to $1.36 \mathrm{mM}$. Due to the stronger hydrodynamic restrictions at higher scale, fedbatch and air extraction improvements lead to an $80 \%$ gain compare to the $30 \%$ gain at small scale.

Yields were inferior to $10 \mathrm{mM}$ of $\mathrm{C}_{6}$-volatile obtained by [28] or by [29], but in our process, the HPL, a membrane bound enzyme, is used in her native form without any extraction by detergent, therefore the produced aromas are suitable for food and beverage products, unlike previously describe production procedures [28-30]. After the synthesis, $\mathrm{C}_{6}$-aldehydes are simultaneously 
extracted from the bio-reactor solution and collected from the cold trap. In these productions, approximately $48 \%$ of the molecules produced were collected in the cold trap; the remaining part was extracted from the bio-reactor solution by absorption on hydrophobic resins. Under these conditions, approximately $90 \%$ of the aldehydes previously in solution are recovered. Afterwards, these GLVs are purified by pilot scale distillation to form a 95\% pure extract (GC purity).

\subsection{GLVs production using recombinant BvHPL}

In a further approach, BvHPL gene was cloned into an $E$. coli strains under high expression level (Improvement $\mathrm{C}$ ) to dispose of pure sugar beet HPL enzymes. Total RNA was extracted from 21 days old plants and a double strand cDNA pool was constructed. By alignment of different HPL sequences from other plant species, we have identified conserved regions of the corresponding HPL gene and designed degenerated primers. PCR with these primers resulted in the amplification of a first $450 \mathrm{pb}$ fragment. Sequencing revealed that this fragment was related to an HPL gene, and RACE-PCR was performed to obtain the corresponding full length DNA fragment named BvHPL (GenBank ID HQ615688), a sequence of $1680 \mathrm{pb}$. The sequence contains an open reading frame of $1464 \mathrm{pb}$ encoding a 488 aa protein. The mass calculated is $54,950 \mathrm{Da}$ corresponding to the average weight of an HPL monomer. BvHPL sequence shows homology between $65 \%$ and $50 \%$, especially with HPLs from the CYP74B family bell pepper [24] (66\%), Nicotiana attuanata (67\%) (unpublished) and castor bean (65\%) (unpublished). The BvHPL gene was introduced in M15 E. coli by a high expression plasmid. The expression of this HPL gene in recombinant strain was achieved at optimum after $72 \mathrm{~h}$ of incubation and upon induction with IPTG $0.1 \mathrm{mM}$. After extraction with lysozymes, high activity levels were detected within the E. coli cells: $11.24 \mu \mathrm{kat} / \mathrm{mL}$ of culture using 13-HPOT as substrate while the homogenized culture medium was found to be free of any activity. The recombinant enzyme was more stable than the native one (data not shown). The six first amino acids, playing a role in protein binding, were removed from sequence and involve into HPL instability phenomenon. Besides, production assays performed in the fully optimized conditions led to higher production of (3Z)-hexenal and (2E)-hexenal (Fig. 3). No HPO derivatives or by-products could be detected. This alternative is advantageous because it does not rely on agricultural condition, harvesting period and plant heterogeneity. It also provides HPL without any undesired hydroperoxidase or aldehydes degrading activity. Nevertheless, necessity of antibiotics and detergents for enzymes extraction step is a serious handicap for developing a natural production process of aromas. Regarding the cost of the extracting medium, the antibiotics and inductor, the scaling-up of this production was not performed at $100 \mathrm{~L}$. A further alternative is the use of excreted HPL produced by eukaryotes strains, this new protocol suppress the necessity of enzymatic extraction but in these conditions HPL activity produced remains often very low e.g. under $1 \mu \mathrm{kat} / \mathrm{mL}$ [31-33].

\subsection{Concluding remarks}

Based on our successful scale-up results, we have developed an original GLVs synthesis procedure from non-valorized biomaterials. Efficient substrate biotransformation is guaranteed by improved substrate addition, mixed extraction and purification system. This aroma production is perfectly suitable for developing a large scale food and beverage aroma production. Furthermore, synthesis of GLVs with recombinant HPL is presented as a suitable alternative with enhanced yield and crop culture independency.
By adaptation and cost reduction of this second technique, high concentrations of $\mathrm{C}_{6}$-volatile can be produced at high scale.

\section{Acknowledgements}

This work was financed by a Walloon region research project. Gigot C. is a recipient of a FRIA grant and Ongena M. is research associate at the FRS-FNRS in Belgium.

\section{References}

[1] Schwab W, Davidovich-Rikanati R, Lewinsohn E. Biosynthesis of plant-derived flavor compounds. Plant J 2008;54:712-32.

[2] Hatanaka A. The biogeneration of green odor by green leaves. Phytochemistry 1993;34:1201-18.

[3] Matsui K. Green leaf volatiles: hydroperoxide lyase pathway of oxylipin metabolism. Curr Opin Plant Biol 2006;9:274-80.

[4] Farmer EE, Alméras E, Krishnamurthy V. Jasmonates and related oxylipins in plant responses to pathogenesis and herbivory. Curr Opin Plant Biol 2003;6:372-8.

[5] Fauconnier ML, Mpambara A, Delcarte J, Jacques P, Thonart P, Marlier M. Conversion of green note aldehydes into alcohols by yeast alcohol dehydrogenase. Biotechnol Lett 1999;21:629-33.

[6] Noordermeer MA, Veldink GA, Vliegenthart JFG. Alfalfa contains substantial 9-hydroperoxide lyase activity and a 3Z: 2E-enal isomerase. FEBS Lett 1999;443:201-4.

[7] US Patents. Process for producing a green leaf essence. 4806379.

[8] US Patents. Method for preparing green aroma compounds. 4769243.

[9] US Patent. Muskmelon (Cucumis melo) hydroperoxide lyase and uses thereof. 7037693.

[10] US Patents. Method for providing green note compounds. 6274358.

[11] Vick BA, Zimmerman DC. Lipoxygenase and hydroperoxide lyase in germinating watermelon seedlings. Plant Physiol 1976;57:780-8.

[12] Hatanaka A, Kajiwara T, Sekiya J, Fujimura K. Participation of 13-hydroperoxide in the formation of n-hexanal from linoleic acid in tea chloroplasts. Agric Biol Chem 1979;43:175-6.

[13] Sekiya J, Kajiwara T, Munechika K, Hatanaka A. Distribution of lipoxygenase and hydroperoxide lyase in the leaves of various plant species. Phytochemistry 1983;22:1867-9.

[14] Matoba T, Sakurai A, Taninoki N, Saitoh T, Kariya F, Kuwahata M, et al. N-hexanol formation from $\mathrm{N}$-hexanal by enzyme action in soybean extracts. J Food Sci 1989;54:1607-10.

[15] Blee E, Joyard J. Envelope membranes from spinach chloroplasts are a site of metabolism of fatty acid hydroperoxides. Plant Physiol 1996;110:445-54.

[16] Padilla MN, Hernandez ML, Perez AG, Sanz C, Martinez Rivas JM. isolation, expression, and characterization of a 13-hydroperoxide lyase gene from olive fruit related to the biosynthesis of the main virgin olive oil aroma compounds. J Agric Food Chem 2010;58:5649-57.

[17] Grechkin AN, Bruhlmann F, Mukhtarova LS, Gogolev YV, Hamberg M. Hydroperoxide lyases (CYP74C and CYP74B) catalyze the homolytic isomerization of fatty acid hydroperoxides into hemiacetals. Biochim Biophys Acta-Mol Cell Biol Lipid 2006;1761:1419-28.

[18] Brash AR. Mechanistic aspects of CYP74 allene oxide synthases and related cytochrome P450 enzymes. Phytochemistry 2009;70:1522-31.

[19] Fauconnier M-L, Perez AG, Sanz C, Marlier M. Purification and characterization of tomato leaf (Lycopersicon esculentum Mill) hydroperoxide lyase. J Agric Food Chem 1997;45:4232-6.

[20] Rodrigo D, Jolie R, Van Loey A, Hendrickx M. Thermal and high pressure stability of tomato lipoxygenase and hydroperoxide lyase. J Food Eng 2007;79:423-9.

[21] Rabetafika H, Gigot C, Fauconnier M-L, Ongena M, Destain J, du Jardin P, et al Sugar beet leaves as new source of hydroperoxide lyase in a bioprocess producing green-note aldehydes. Biotechnol Lett 2008;30:1115-9.

[22] Gardner H, Plattner R. Linoleate hydroperoxides are cleaved heterolytically into aldehydes by a Lewis acid in aprotic solvent. Lipids 1984;19:294-9.

[23] Noordermeer MA, van Dijken AJH, Smeekens SCM, Veldink GA, Vliegenthart JFG. Characterization of three cloned and expressed 13-hydroperoxide lyase isoenzymes from alfalfa with unusual $\mathrm{N}$-terminal sequences and different enzyme kinetics. FEBS Lett 2000;267:2473-82.

[24] Matsui K, Shibutani M, Hase T, Kajiwara T. Bell pepper fruit fatty acid hydroperoxide lyase is a cytochrome P450 (CYP74B). FEBS Lett 1996:394:21-4.

[25] Gomi K, Yamasaki Y, Yamamoto H, Akimitsu K. Characterization of a hydroperoxide lyase gene and effect of C6-volatiles on expression of genes of the oxylipin metabolism in Citrus. J Plant Physiol 2003;160:1219-31.

[26] Howe GA, Lee GI, Itoh A, Li L, DeRocher AE. Cytochrome P450-dependent metabolism of oxylipins in tomato. Cloning and expression of allene oxide synthase and fatty acid hydroperoxide lyase. Plant Physiol 2000;123:711-24.

[27] Noordermeer MA, Goot W, Kooij AJ, Veldsink JW, Veldink GA, Vliegenthart JFG. Development of a biocatalytic process for the production of C6-aldehydes from vegetable oils by soybean lipoxygenase and recombinant hydroperoxide lyase. J Agric Food Chem 2002;50:4270-4. 
[28] Németh AS, Márczy JS, Samu Z, Háger-Veress Á, Szajáni B. Biocatalytic production of 2(E)-hexenal from hydrolysed linseed oil. Enzyme Microb Technol 2004;34:667-72.

[29] Márczy JS, Németh Á, Samu Z, Háger-Veress Á, Szajáni B. Production of hexanal from hydrolyzed sunflower oil by lipoxygenase and hydroperoxide lyase enzymes. Biotechnol Lett 2002;24:1673-5.

[30] Rehbock B, Ganszer D, Berger RG. Efficient generation of 2E-hexenal by a hydroperoxide lyase from mung bean seedlings. Food Chem 1998;63: 161-5.
[31] Bourel G, Nicaud JM, Nthangeni B, Santiago-Gomez P, Belin JM, Husson F. Fatty acid hydroperoxide lyase of green bell pepper: cloning in Yarrowia lipolytica and biogenesis of volatile aldehydes. Enzyme Microb Technol 2004;35:293-9.

[32] Atwal AS, Bisakowski B, Richard S, Robert N, Lee B. Cloning and secretion of tomato hydroperoxide lyase in Pichia pastoris. Process Biochem 2005;40:95-102.

[33] Santiago-Gómez MP, Thanh HT, De Coninck J, Cachon R, Kermasha S, Belin J-M, et al. Modeling hexanal production in oxido-reducing conditions by the yeast Yarrowia lipolytica. Process Biochem 2009;44:1013-8. 